Article

\title{
The New Educational Pastorate: Link Workers, Pastoral Power and the Pedagogicalisation of Parenting
}

\author{
Nathan Fretwell (D) \\ Department of Education, Middlesex University, London NW4 4BT, UK; n.fretwell@mdx.ac.uk
}

Received: 30 September 2019; Accepted: 29 January 2020; Published: 31 March 2020

check for updates

\begin{abstract}
Home-school relations, home learning and parental engagement are prominent educational policy issues, constituting one aspect of a wider parenting support agenda that has suffused the landscape of social policy over the last two decades. This article examines a parenting support initiative distinctive for its use of link workers in mobilising 'hard to reach' parents to engage more effectively with their children's education. Drawing on qualitative data gathered during the evaluation of the initiative, the article frames link worker-parent interactions as a form of everyday government and pastoral power. Link workers constitute a new educational pastorate; through friendship, care and control they exercise pastoral power over parents. Building on recent research into the role of 'pastors' in producing neoliberal subjectivities within the National Health Service, the article foregrounds their efforts to foster responsible, self-disciplined agency in parents. Link workers, it is argued, contribute to a responsibilisation and pedagogicalisation of the family, which has produced new figures of mothering/parenting, reconfigured the meaning of the home and extended the scope of state intervention into family life.
\end{abstract}

Keywords: link workers; parental engagement; pastoral power; governmentality; Foucault; pedagogicalisation; responsibilisation

\section{Introduction}

Home-school relations, home learning and parental engagement are prominent educational policy issues, constituting one aspect of a wider parenting support agenda that has suffused the landscape of social policy over the last two decades (Daly 2015). Though framed as common-sense strategies for improving family outcomes, parenting support policies have intensified political scrutinisation of family life (Lee et al. 2014). This "zealous politicking of intimate family relationships" is driven by a moral narrative positing inadequate parenting as the root cause of social problems, and a doxic belief in the power of 'good' parenting to mitigate for systemic disadvantage (Jensen 2010). Parents are routinely positioned in this discourse as both scourges and saviours of society. Disadvantaged families, in particular, are subject to often fierce public disapprobation and, despite the prominence of the gender-neutral term 'parent', it is invariably mothers who are addressed by policy and held responsible for delivering on its aims (Cole 2007; Vincent 2012; Daly 2013). ${ }^{1}$ Within this policyscape, the process of raising children is decoupled from social context, producing the fantasy of an unencumbered parent unconstrained by and able to rise above any adverse eventuality, and concerns for addressing

1 Whilst the parent participants in the study were overwhelmingly female, and the author recognises that the gender-neutral term 'parent' dissimulates gendered implications of parenting support, the term has been retained to maintain consistency with the original framing of the initiative and the convention in the wider policy literature. 
inequitable social conditions are displaced by an inordinate emphasis on parental character and conduct as the key locus for intervention.

This article draws on the commissioned evaluation of a parenting support initiative aiming to improve educational outcomes for white British, working-class pupils by mobilising 'hard to reach' parents to engage more effectively with schools and at-home learning. Established by an inner-London local authority, the Raising Achievement for White British Pupils project was piloted during the 2014-15 school year. ${ }^{2}$ The distinctive feature of the project was its focus on deploying link workers to provide tailored support to parents and to serve as a bridge between home and school. With the intention of maximising parents' participation, the strategic decision was made that the link workers would be recruited from within the community; that is, they should have close ties to the local area and come from white working-class backgrounds themselves. For similar reasons, it was decided that the link workers would be based within the community rather than in schools. Two mothers from white working-class backgrounds with prior experience of parenting support and youth work were employed as the link workers responsible for delivering the project. In bridging home and school, the link workers supported parents in schools and advocated on their behalf. They also sought to improve the profile of this cohort of parents by raising awareness within schools of the particular challenges they face. However, in common with other areas of parenting support, the project focused primarily on what parents do rather than on the wider issues affecting family life and educational outcomes. So, whilst organisers acknowledged that achievement is affected by a complex suite of issues, attention principally fell on the perceived "misalignment between parents and schools" (Project Aims document), with the aim of improving home-school relationships by developing parents' communication skills, fostering effective engagement in at-home learning and encouraging the utilisation of community resources. Link workers, then, were tasked with changing the conduct and attitudes of parents in relation to education and helping them develop skills regarded as essential for becoming better parent-educators.

Link workers are common in health settings (Wildman et al. 2019) and a growing presence within education (Demie et al. 2008; Daly and Bray 2015; Fretwell et al. 2018). However, to date, their function in educational settings remains under-explored. The intention of this article was to develop this field of inquiry by focusing on the link workers' role in governing parents. Framed as a critical, theoretically informed examination of link worker practice, the article centres closely on data collected from the two link workers and foregrounds their experiences of developing the role and delivering on the project's objectives. Data were gathered from the two link workers across a series of extensive interviews over the course of the pilot, and the decision to focus almost exclusively on their perspective in this article was motivated by the aim of exploring as fully as possible how link workers construct, rationalise and understand their role, thereby providing a rich, detailed insight into their self-conceptualisation and the strategies they devised to deliver on their aims. With this in mind, it is not the intention here to enter into detailed discussion of the experiences of other stakeholders in the project (e.g., parents). However, this article forms part of a wider study rooted in the original evaluation, and other publications have drawn more extensively on the wider sample of participants and explored parents' and other stakeholders' experiences in greater detail (Fretwell et al. 2018; Fretwell).

The chief argument proposed here is that link workers constitute a new educational pastorate; through friendship, care and control, they exercise pastoral power over parents. Building on recent research into the role of 'pastors' in producing neoliberal subjectivities within the National Health Service (Waring and Martin 2016), the article foregrounds link workers' efforts to foster responsible, self-disciplined agency in parents. The link workers, it is argued, contribute to a responsibilisation and pedagogicalisation of the family, which has produced new figures of mothering/parenting, reconfigured the meaning of the home and extended the scope of state intervention into family life. However, given

2 To preserve the anonymity of participants, a pseudonym has been used for the title of the project. For the same reason, the funder, an inner-London local authority, has not been disclosed. 
the lack of sociological inquiry into the role and function of educational link workers, further research is required from other settings and other contexts to corroborate this account. In part, this study thus constitutes an invitation to further development of the field.

The article opens by outlining the methodology employed in the evaluation of the project. This is followed by a broader, contextualising discussion of the pedagogicalisation of family life before turning to situate the new educational pastorate in the context of Foucault (2009) genealogy of pastoral power. The article then explores how pastoral power is deployed as a technique for governing parents' conduct and how care and control become entangled in link worker-parent interactions. I conclude by calling for further research into the growing use of link workers within education and the need for more just policy solutions to educational underachievement that address the inequitable conditions of parenting, not merely the conduct of parents themselves.

\section{The Pilot Project: Background and Evaluation}

As discussed above, the project focused on improving white British, working-class pupils' attainment by mobilising parents to become more engaged with their children's education. Educational underachievement amongst this cohort of pupils had long been recognised as a concern within the Borough, and the project was motivated by the belief that more could be done within the area to support the white British community and improve their educational prospects. Parents were recruited largely through school referrals. At the behest of the local authority, participating schools selected parents according to the identity-based criteria, parents' perceived level of engagement and children's educational performance. However, as participation was voluntary, a key remit of the link workers' role was building effective relationships with parents and encouraging them to participate. Whilst ultimately concerned with improving educational attainment, the project constituted a relatively broad form of parenting support, combining an emphasis on parental engagement in education with activities aimed at helping parents (re)enter employment and/or further education and training. The link workers supported parents across both areas, organising workshops and activities, facilitating events and providing drop-in sessions. They also organised social events such as book clubs and coffee mornings, and, as discussed below, provided more ad-hoc forms of pastoral, holistic support, ranging from impromptu childcare to helping out with housing issues. The link workers' role was thus extremely broad if not rather ill-defined and nebulous. As Denise, one of the two link workers responsible for delivering the project, attested, "it was a blank page when we first started."

Data in this article draws from the evaluation of the pilot project during 2014-15. The evaluation reported on the effectiveness of the pilot in engaging parents, assessed the strategies employed by the link workers for this end and provided recommendations to inform future delivery. A mixed-methods approach employing qualitative methods of data collection was adopted. Methods utilised included: semi-structured interviews, focus groups, paired interviews and observations of key events. Data were collected across three key phases of the pilot as identified by the project organisers: (1) relationship building; (2) parent-led interventions; and (3) celebrating achievement. The two link workers were interviewed across all three phases, as were parents (n.11). Data were collected from senior school staff (n.16) and members of the local authority (n.4) in the first two phases. In total, across the three phases, 19 interviews were conducted with parents (including two focus groups); 19 interviews with school staff (including five paired interviews); two group interviews with members of the local authority; and five interviews with the link workers (consisting of two individual interviews and three paired interviews). Informed consent was obtained from all participants and pseudonyms have been used throughout, including for the title of the project.

In terms of outcomes, parents valued the project and the support the link workers provided. They were also enthusiastic about having the opportunity to acquire skills to enable them to engage more effectively in at-home learning and improve their own employment prospects, as well as for building networks of peer support. Schools were more equivocal. Whilst the majority remained positive about the project and some reported improved relationships with parents, concerns were 
raised about the actual remit of the link workers and the effectiveness of the project in helping improve attainment. It was beyond the scope of the evaluation to report on links between parents' level of engagement and pupils' attainment. However, the evaluation did reveal that the link workers had considerable success in engaging parents, and it is their efforts in this regard on which this article is focused.

\section{The Pedagogical Family}

The family, Foucault argues, is central to the functioning of power. It is a "fundamental relay" and "privileged instrument" for governing the population (Foucault 2009, pp. 104-5). "[W]hen one wants to obtain something from the population concerning sexual behaviour, demography, the birth rate, or consumption," he maintains, "then one has to utilize the family" (ibid, p. 105). Hunter (1994) genealogy of modern schooling develops this point by emphasising the centrality of schools to processes of governing in and through the family. Modern education, he contends, is marked by "a series of historical accommodations between state schooling and the family" (Hunter 1994, p. 127). From the post-war period onwards, the family has been co-opted as an "auxiliary pedagogical domain", an "annex of the school," where non-coercive methods for reinforcing pedagogical norms have come to predominate (ibid, p. 126). Whilst disciplinary elements undoubtedly remain, and schools continue to function as "minute social observatories" for supervising children and adults (Foucault 1991, p. 211), the family is increasingly perceived not as a rogue element requiring correction, but as a "nursery of social aspiration whose internal relations require cultivation and management" (Hunter 1994, p. 122). This process has arguably reached its apex at the current juncture. The family-school nexus has become a key means for governing the family by nurturing subjectivities consistent with neoliberal conceptions of responsible parenting, wherein the family is reconceived as an incubator of human capital. This becomes even more pronounced as the "pedagogical colonisation of the family" (ibid, p. 135) is uncoupled from formal education to constitute an essential component of parenting support more generally.

As the locus of responsibility for children's future outcomes shifts from state institutions to families, parents are charged with reversing educational inequalities. They are constructed as surrogate educators, as "a child's first and enduring teachers" (Department for Education and Employment (DfEE)), such that successful parenting demands becoming an effective pedagogue (Popkewitz 2003). If pedagogicalisation produces new figures of parenting, it also reconfigures the meaning of the home. The home is reconceptualised as the optimal learning environment. Despite being described as the "last taboo of education policy" (Hinds 2018), the home learning environment (HLE) has been a persistent policy concern for at least two decades. A familiar rhetoric drives this concern:

[W] know that the early home learning environment is the single biggest influence on a child's development-more important than material circumstances or parental income, occupation or education. Indeed, the quality of a child's relationships and learning experiences in the family has more influence on achievement than innate ability, material circumstances or the quality of pre-school and school provision. (Allen 2011, p. 57)

Pedagogicalisation blurs boundaries between home and school, parent and teacher (Gillies 2011). Moreover, it transforms the intimate process of raising a child into a skillset acquired through expert intervention: parents must be taught strategies for learning; they must be instructed in how to construct an effective HLE; they must develop desirable pedagogical behaviours and habits.

Research has long reported how policies around parental engagement and the HLE normalise white middle-class parenting practices (Reay 2008; Vincent and Maxwell 2016), place uneven burdens on disadvantaged parents (Reay 1998; Crozier and Reay 2005; Vincent 2012) and can lead to the policing of families (Crozier 1998; Gillies 2011). But as Hartas $(2014,2015)$ analysis of Millennium Cohort Study data reveals, social class and levels of maternal education significantly outweigh parenting practices and the quality of the HLE in terms of their impact upon children's educational outcomes. 
This challenges the doxic belief in the power of parenting and its mantra that "[w]hat parents do is more important than who they are" (Allen 2011, p. xiv). Targeting behaviour change as a means for addressing long-standing educational and societal inequalities deflects attention away from the material conditions of the family, conveniently bypassing difficult political questions concerning the (re)distribution of social wealth. In Goodall (2019) pithy formulation, it is a case of solving parents whilst absolving the system.

Raising Achievement shares this focus on parental conduct and behaviour. The link workers are deployed to pedagogicalise the family, to change parental behaviours around education and to reconstitute parent subjectivities. Through close care and support, they strive to produce the active, responsible parent-educators neoliberalism desires. However, Raising Achievement also functions as a means for governing the community. By specifying this cohort of parents-as 'hard to reach', white British, working-class-it creates community where heretofore none existed. Making the population visible enables it to be more effectively governed: "[it] is a matter of defining boundaries rendering that within them visible, assembling information about that which is included and devising techniques to mobilize the forces and entities thus revealed" (Rose 1999b, p. 33). By naming the community, framing it as deficient and mobilising it to act, the project targets not just individual parents but the 'flock' as well. The new educational pastorate governs "each and all" (Foucault 2002).

\section{Link Worker as 'Pastor'}

Considered a "prelude" to governmentality and a "decisive moment" in the development of Western political institutions (Foucault 2009, pp. 184-85), pastoral power occupied a prominent place in Foucault's lectures of the late 1970s/early 1980s. This salvific form of power first emerged, Foucault contends, within the ancient Hebraic tradition which modelled government on the relationship between shepherd and flock. The shepherd-ruler, on this account, cares for the flock, looks out for its welfare, and exercises vigilance to ensure each sheep remains within the fold. Pastoral power is hence a fundamentally beneficent power: through "constant, individualized, and final kindness" the pastor watches over the flock and attends to its salvation (Foucault 2002, p. 302). It is also an individualising power. The pastor cares for the good of each and all: "He does everything for the totality of his flock, but he does everything also for each sheep of the flock" (Foucault 2009, p. 128). It is through Christianity, however, that pastoral power becomes crucial to the "history of the present":

In Christianity the pastorate gave rise to an art of conducting, directing, leading, guiding, taking in hand, and manipulating men [sic.], an art of monitoring them and urging them on step by step, an art with the function of taking charge of men [sic.] collectively and individually throughout their life and at every moment of their existence. (ibid, $p .165$ )

In honing this art of "everyday government" (ibid, p. 151), the Christian pastorate permits the wider dissemination of pastoral power throughout society as a general "model and matrix of procedures for the government of men [sic.]" (ibid, p. 147). It has been absorbed by the modern state and, as the salvation of each and all turns to more 'worldly' aims-health, well-being, security, etc.-the agents of pastoral power proliferate and expand across the social field (Foucault 2002, p. 334).

Deploying link workers to enhance parental engagement and improve home-school relations represents a contemporary expansion of the field of pastoral power. They constitute a new educational pastorate. The link worker's 'flock' is a community deemed 'hard to reach', disengaged and at risk of failing in their duties as parent-educators. Saving the community from the blight of educational underachievement hence necessitates working on parents' souls. As a technology of government, pastoral power serves to align citizens' conduct with dominant political rationalities, enabling the "aspirations of government" to infiltrate into "the very interior of our existence and experience as subjects" (Rose 1999a, p. 11):

[P]astors are crucial nodes in neoliberalism who translate prevailing mentalities or discourses into specific life worlds [... ] support individuals to internalise and embody new subjectivities [and] 
reinforce expected social conduct and choices through either direct forms of surveillance or by promoting technologies of the self. (Waring and Martin 2016, p. 138)

It is through the pastorate that governmentality gains purchase in citizens' everyday lives. The link worker, as 'pastor', enables the state to "govern at a distance" (Rose 1999b), translating pedagogical norms and neoliberal mentalities into parental self-government.

We live in an era of parental determinism and parent-blame (Furedi 2008; Jensen 2018), where social problems from rising inequality to educational underachievement are attributed to inadequate parenting and intimate family life is subject to ever-increasing public scrutiny. Within this context, "the problems of problematic persons are reformulated as moral or ethical problems, that is to say, problems in the ways such persons understand and conduct themselves and their existence" (Rose 1999b, p. 268). The way parents raise their children, their relationships, their values and aspirations, indeed, their very being as parents, are reconfigured as political concerns. In this modern salvation narrative, parents are positioned as saviours of the nation, but saviours who must first be saved from themselves. Contemporary government increasingly functions through the medium of "non-coercive suggestions" (Jones et al. 2013, p. 18), and this is where the importance of the pastorate lies. In caring for their 'flock', the link workers encourage parents to become reflexive, responsible and self-governing, to adopt and internalise normative parenting ideals (Dahlstedt and Fejes 2014). They pursue this by working directly on the conduct of parents. Pastoral power is exercised in a friendly, supportive fashion to mobilise parents to effect desired changes in themselves and in the way they raise their children.

\section{Exercising Pastoral Power: The Power of Friendship}

Pastoral power works through the agency of those over whom it is exercised. The flock has to express a willingness to be led and be receptive to the guidance offered. It is a "thoroughly affective" relationship (Golder 2007, p. 167). To function effectively the pastor must also have intimate knowledge of the flock. Pastoral power "cannot be exercised", Foucault contends, "without knowing the inside of people's minds, without exploring their souls, without making them reveal their innermost secrets. It implies a knowledge of the conscience and an ability to direct it" (Foucault 2002, p. 333). For this to occur, however, the flock must trust the pastorate.

The affective ties between pastor and flock are crucial to understanding link worker-parent interactions. Like the Home-Start volunteers in Fisher et al.'s study, link workers operate in the "liminal spaces of parenting support" (Fisher et al. 2019, p. 250); occupying a threshold position between home and school, professional and friend. Creating affinity and establishing friendships with parents was essential in building trust. It afforded link workers a deeper insight into parents' lives and enabled them to exercise power in a supportive fashion (Wainwright and Marandet 2013). The link workers noted, for instance, that parents "see [us] as friends really". For their part, parents were quick to attest to how "very warm," "open," "approachable," "friendly" and "down to earth" they considered the link workers to be. One parent even indicated that "[i]t's like you've known them for years." Tactics adopted by link workers for developing friendly, trusting relations included distancing themselves from institutions that caused parents unease (e.g., schools, social services) and trading on their backgrounds as white working-class women themselves. The two link workers-Denise and Yvonne-emphasised the importance of shared identity in establishing trust: "maybe with parents you can build more of a relationship when you're like them so to speak." They also believed it offered an insight into the mindset of parents which would help them provide more effective guidance and support. It was through these displays of affinity and the credibility they generated that the link workers were able to position themselves as trusted representatives of the community, as 'cultural brokers' (Martinez-Cosio and Martinez Iannacone 2007) between home and school capable of appreciating and defending parents' interests. For parents, this had the added effect of making them feel equal and respected partners in the relationship. As Lily conveyed, this was in stark contrast to their experiences of engaging with other services: "you feel like you're not being looked down on, you're on a level with someone. And whereas other services you always feel 
like we're supporting you because you can't do this or because you're not capable of doing this on your own or whatever." (For further discussion of this point see: (Fretwell et al. 2018)).

Making parents feel valued and important was also key to building positive relations. Link workers provided a "sounding board" for parents—a sympathetic forum where they could "let off some steam" and talk about challenges they face. Parents obliged. Indeed, link workers expressed surprise at just "how much they wanted to share and talk," often concerning the most intimate details of their lives. Given parents' general distrust of public authorities, their candidness in this regard is indicative of the depth of bond that developed. The affinity was mutual. Yvonne, for instance, spoke of her admiration for the parents: "we were really inspired by things that they've done and things that they've overcome." Link workers' dedication further consolidated the relationship. Denise and Yvonne insisted they would remain contactable during the school holidays, despite not being officially contracted during this period: "If someone's got a crisis or they want to see us, we're both local so we're not gonna say, 'No. We're on holiday.'" These efforts to foster friendly, trusting relations established the groundwork for subsequent undertakings to steer parents' conduct.

The link workers' role is distinctive within education for its holistic attention to parent's well-being. It extends beyond the provision of pedagogical guidance to encompass supporting parents in their everyday lives. In "all these little things" they do to alleviate parents' burdens, the new educational pastorate takes shape:

I'm doing so many different things with parents, I'm mentoring children in school, I'm making regular visits to two families now out of school that need support. It could turn out to be even, supporting, helping them filling out forms, some problems with housing. I'm dealing with a family that they're not getting anywhere with some repairs that need to be done at home. So, it's really varied, any form of ... if I can help in any way I will, if I can't then there may be an organisation within [the Borough] that I can put them on to. (Denise, Link Worker)

This level of holistic care exceeds the official parameters of Raising Achievement to incorporate elements of general social support. However, such support is considered a necessary prelude for tackling the specific issue of educational achievement:

I just want the families to benefit from this work and whether that's their children's schooling which is the main-that is the main point-but I feel that if the families are a bit more stable then it starts rolling out into the child's life. So, if mum's life is a mess, obviously I feel the child's life often is as well [ ... ] if we can sort the family out in any way shape or form then hopefully it starts reflecting on the children. (Denise, Link Worker)

'Sorting out' the family, Denise posits, is a route to achieving the longer-term goal of improving educational outcomes. But, again, this intensive work with parents is enabled by the prior establishment of friendly, trusting relations.

The prominence of friendship in link worker-parent interactions places the new educational pastorate in a historical lineage with roots in nascent family social work. Common to this lineage is the instrumental use of friendship to effect changes in families' conduct. Robinson (2000) fascinating account of Octavia Hill house managers in early twentieth century South Africa, for example, describes the use of a "friendship model of management" to improve tenants' domestic standards. Under their tutelage, tenants were induced to become "responsible, self-disciplined citizens" through a process of "gentle and friendly rehabilitation" (ibid, pp. 71, 82). Similarly, the Family Service Units documented by Starkey employed friendship with parents as a means of encouraging "socially accepted standards of domestic organisation and child-care" (Starkey 2000, p. 20). These historical examples cast friendship as a matrix for exercising pastoral power. "Friendship with a purpose" (Starkey 2000) or "contrived conviviality" (Fretwell et al. 2018) is also evident in contemporary parenting support. In their account of family learning initiatives, for instance, Wainwright and Marandet describe how "power is configured in a 'supportive' way that trades on friendly relations to encourage mothers to participate" (Wainwright and Marandet 2013, p. 506). 
In Raising Achievement, nurturing affinities made parents more amenable to guidance. As Yvonne insisted, "[t]hey're happy to do whatever we ask them, they're so lovely, they really are." It functioned as a technique for fostering responsible self-government:

[T]heir confidence has just gone through the roof I think since they've been working with us on the project. And I think we do a lot in those workshops, not just about what your kids are learning at school but about your communication and how to bring up your issues in a controlled and calm way and things like that. So, I think they're learning a huge amount about how to communicate with the school and not go in like a bull in a china shop like some of them do or used to do. (Yvonne, Link Worker)

Through their care and support, guidance and instruction, link workers induce parents to internalise behaviours commensurate with the dominant normative order. For this form of power to be sustainable, though, it requires the active investment of its subjects; they must recognise that in its exercise their needs are being met (Robinson 2000). Unsurprisingly, parents in the study wanted the best for their children and the link workers activated this desire. They encouraged parents to adopt pedagogical norms so that they might better serve their children's interests. They spurred parents to become better role models by enjoining them to participate in workshops aimed at their own self-improvement, and they fostered responsible self-government so parents might enter into more productive alliances with schools. Pastoral power excites parents' desires, enabling governmental rationalities to shape the parental soul. "Each normal family", Rose writes, "will fulfil its political obligations best at the very moment it conscientiously strives to realize its most private dreams" (Rose 1999a, p. 213). However, since this form of power eschews coercion and operates through the mobilisation of conscience, it is inherently fragile (Fretwell et al. 2018). There is always the possibility that the 'flock' might refuse the ministrations of the pastorate. There are aspects of link worker practice that aim to mitigate this risk, but in ways that suggest complex entanglements between care and control.

\section{Entanglements of Care and Control}

Pastoral power operates "at the nexus between discipline and subjectification", serving to both discipline subjects and nurture desirable subjectivities (Waring and Latif 2018, p. 1081). In order to illustrate the entanglements of care and control in link worker-parent interactions, I draw in this section on two exchanges. The first exchange highlights tensions in efforts to engage parents and the disciplinary aspect of the pastoral gaze. The second centres on the use of confession as a technology obligating parents to manifest their truth as 'inadequate' and in need of guidance and supervision. In both cases, care and control are mutually implicating.

Link workers exercise pastoral power through 'noisy surveillance' (Robinson 2000). This form of surveillance is overt and relational, it involves listening, persuasion, friendship, trust and sympathy. It transforms interactions between service-providers and service-users into a means for garnering insights into individuals' lives so that they might be better supervised and managed: link workers telephone parents, make home-visits, call at schools, insinuate themselves within the community and so forth. Whilst it would be a mistake to view this process as wholly intrusive, given that in many respects it is negotiated in advance (Robinson 2000), the following exchange nevertheless suggests that parents have limited scope for refusing the advances of link workers.

Yvonne: They see us here every day; we're like where they live, where they are.

Denise: One of the mums we get our rolls from her shop, just down the end there, so she can't escape us. [laughter] But it is ...

Yvonne: And they're dropping their kids here. So, like yesterday there's one we had trouble getting on the phone, so Denise just went down there at three thirty and found her in the playground.

Denise: And she was like: "Oh, I'm so sorry. I'm not blanking you". It's like "Shut up, calm down, it's fine!" 
Yvonne: It's in walking distance, the school. So, with the primaries specifically if we're having trouble getting hold of them, we know we can just hang around outside and catch them. "Oh, fancy meeting you here!" [laughter]

Denise: But it's so funny. Because again like [parent] yesterday, she's been really, you know, and it is "Oh, I'm sorry, I'm not blanking you." Actually, but you are! You've had like... [laughter] and that's what's so funny with them. And then she's all sorry. But yes, she signed the forms and that was it.

The ambiguity in the opening sentence of this exchange exemplifies tensions between care and control in link worker-parent interactions. Their ubiquitous presence in the locale suggests they are expertly placed to provide support wherever it is needed, but it also suggests that parents are unable to escape their attention: link workers watch over the flock at all times and in all places. Foucault writes that pastoral power is "coextensive and continuous with life" (Foucault 2002, p. 333). Here, even the mundane activity of buying lunch transforms into an opportunity for surveilling parents. Link workers dogged efforts to recruit and engage parents, to 'catch' them as they put it, confirms the sense that programmes targeting particular cohorts can lead to "the literal pursuing of mothers" (Wainwright and Marandet 2013, p. 516). Elsewhere, for instance, they speak of the necessity of "[s]talking them a bit": "[y]ou've got to chase them. They don't answer their phones." Continuous communication and perseverance were identified as hallmarks of the link workers' approach, but whilst this was framed as "encouraging" rather than "badgering" parents, little consideration is given to the fact that their gentle harrying and friendly persistence might be coercing parents' participation. 'Blanking' the link workers, it would seem, is not a viable option. Positioned between home and school and between a professional and a friend, the link workers' liminal status widens the pastoral gaze. It expands the scope for providing tailored support, but it also constrains parents' choices.

The second exchange sees the two link workers addressing discrepancies between parents' and children's accounts of how often they discuss school learning together and their devising of a strategy for mobilising parents to become more engaged.

Yvonne: I think the next bit for us, which we're going to talk with [project manager] at the next meeting, is about how we-anonymously, not on a personal level like "Your kid said this", but in a research way-share that information with the parents at some point throughout the workshops. I think it's quite powerful [ ... I I think it's important for us to say: "95\% of you guys said you talk to your kids every day, but when we've surveyed the kids only $20 \%$ have said that their parents ... and why is there that?" I think it's really powerful and I think they need to know that.

Denise: They need to know. Yeah.

Yvonne: We just need to find a way of doing it, so it's not ...

Denise: Yeah

Yvonne: ... making people feel, you know, bad personally. You want them to feel bad, as in collectively_-"Oh dear, that's so sad, we must change that"-but we don't want anyone to feel like freaks. But I think they do need to hear it. And, again, not now, I think that's later. When they do ...

Denise: I think there'll be a way of ...

Yvonne: When they're doing the course of workshops...

Denise: Yeah, absolutely...

Yvonne: ... about engaging with their learning; something we share in a kind of educational way. 
This exchange foregrounds relations between truth and power. In his later work, Foucault argues that "the exercise of power is almost always accompanied by a manifestation of truth" (Foucault 2012, p. 6). Parents are exhorted here to face up to the truth of their own inadequacies. They must recognise this truth and be guided by it. Whilst link workers mainly elicit parents' truth voluntarily through the medium of friendship, as figures who can "listen to them and sympathise with them," the emphasis shifts here to the "compulsory extraction of truth" through confession (Foucault 2009, p. 185); an alethurgic process involving "[g]overning the being-other through the manifestation of the truth of the soul, so that each can earn his [sic.] salvation" (Foucault 2012, p. 161). Parents must confess their failings so they can be saved; which is to say, led by the link workers to become 'good,' responsible parent-educators devoted to their children's education. The evident distrust of parents' testimonies, and it is striking that doubt is cast solely upon the veracity of parents' accounts, constructs parents as failing in their duties. The strategic use of shame as a means for correcting parental behaviours is proposed here as a collective solution for tackling inadequate engagement. It is a technique for managing the 'flock'. The community as a whole is compelled "to discover, deep within themselves, secrets that elude them" (ibid, p. 83) and to take responsibility for changing the way they engage with their children's education. Nevertheless, the link workers are clearly animated by care and concern. They are sensitive to how their ministrations will be received and have the future well-being of families in mind. Care and control weave together in their efforts to save parents' souls.

These two exchanges throw light on the disciplinary aspects of pastoral power, where efforts to control and correct parents become more pronounced. It is important, though, not to diminish the positive effect initiatives like Raising Achievement can have on parents' lives (Bond-Taylor 2016; Wainwright and Marandet 2017). Indeed, parents roundly praised the link workers and welcomed the initiative as a long-overdue investment in the community. Parents valued the security it provided by giving them a supporting voice in schools, the social network it helped establish with other parents, the practical assistance it offered in accessing relevant services and resources and the opportunities it provided for gaining new skills. As one parent effused, "I think this is a brilliant thing what they're actually doing $[\ldots]$ we never had all this before."

It is also important to recognise that the pastorate itself is constituted in and through neoliberal discourses (Waring and Latif 2018). Link workers are tasked with recruiting, engaging and changing parents, and their livelihood ultimately depends upon how successful they are in achieving these aims. Responsibilisation and pedagogicalisation shape the pastorate, define its contours and drive its work. It is not enough for the pastorate to passively respond to parents' needs; they must be evangelical. Pastors must internalise these discourses and live them as their own so they can impart them more effectively onto parents. In this regard, link workers are unwitting agents in a political project that transfers the burden of reversing educational inequalities onto parents whilst simultaneously deflecting attention away from wider contextualising factors like material poverty, which impact educational attainment and which require robust political solutions.

\section{Conclusions}

As accountability for children's future outcomes shifts from the state to the family, concern for the adverse environmental conditions affecting families' lives has been displaced by interventions aimed at renovating parenting practices and behaviours as a means of resolving long-standing social inequalities. This has given rise to a new class of paraprofessionals across the social policy domain who are tasked with encouraging desirable parental behaviours and promoting the power of 'good' parenting as capable of mitigating social disadvantage (Daly 2015; Gillies et al. 2017; Lee et al. 2014). The link workers in this study constituted a particular rendering of the parenting support agenda within the field of education. In this article I have focused on their efforts to enhance parental engagement in education through the provision of holistic care and support. Drawing on the Foucauldian notion of pastoral power as a form of everyday government, I argue that the link workers constitute a new educational pastorate. In common with early family social work (Robinson 2000; Starkey 2000), link workers 
exercise pastoral power through the medium of friendship, building affinity and trust with parents as a foundation on which to ground subsequent efforts to change parental behaviours. Operating in the liminal space between home and school and between a professional and a friend (Fisher et al. 2019), link workers capitalise on conviviality to mould parents' conduct and character in conformity with state-sponsored pedagogical norms. However, the pastoral gaze contains a disciplinary as well as a subjectifying aspect (Waring and Latif 2018). Care and control entangle in link worker-parent interactions as parents are obliged to recognise their failings and encouraged to undertake necessary work on themselves through practices of friendly compulsion.

This article contributes to recent efforts to throw empirical light on the processes by which governmentality gains purchase in the everyday lives of citizens (Martin and Waring 2018). The new educational pastorate translates discourses of responsibilisation and pedagogicalisation into parents' life worlds and serves as a crucible out of which neoliberal parental subjects are formed. The paradox, however, is that this is both coercive and empowering (Wainwright and Marandet 2017). Link workers can and do provide a valuable service for parents, and the latter genuinely appreciated their guidance and support. Perhaps, then, echoing Foucault (2002, p. 330), link workers have a role to play in struggling against this 'government of individualization' as defenders of parents' interests, applying pressure for political solutions to social inequalities and greater state accountability for social (in)justice. It is unlikely, of course, that all educational link workers function in the ways outlined here, and instances of more subversive practice may well exist. Further research is hence needed into the use of link workers in education, which could take this work forward and which might point towards ways in which the role can work critically for the benefit of families without reproducing the political dogma that what parents do is more important than who they are.

Funding: This article draws on data from a funded evaluation. However, to preserve the anonymity of the participants the original funding body - a local authority — cannot be disclosed.

Acknowledgments: The author would like to thank the local authority that commissioned the research and all of the participants for sharing their experiences. He would also like to thank the following colleagues who contributed to data collection: Jayne Osgood, Gill O'Toole, and, Maria Tsouroufli.

Conflicts of Interest: The author declares no conflict of interest.

\section{References}

Allen, Graham. 2011. Early Intervention: The Next Steps. An Independent Report to Her Majesty's Government. London: Crown Copyright.

Bond-Taylor, Sue. 2016. Domestic Surveillance and the Troubled Families Programme: Understanding relationality and constraint in the homes of multiply disadvantaged families. People, Place and Policy 10: 207-24. [CrossRef]

Cole, Barbara. 2007. Mothers, gender and inclusion in the context of home-school relations. Support for Learning 22: 165-73. [CrossRef]

Crozier, Gill. 1998. Parents and schools: Partnership or surveillance? Journal of Education Policy 13: 125-36. [CrossRef]

Crozier, Gill, and Diane Reay, eds. 2005. Activating Participation: Parents and Teachers Working towards Partnership. Stoke-on-Trent: Trentham Books.

Dahlstedt, Magnus, and Andreas Fejes. 2014. Family makeover: Coaching, confession and parental responsibilisation. Pedagogy, Culture \& Society 22: 169-188.

Daly, Mary. 2013. Parenting support: Another gender-related policy illusion in Europe? Women Studies International Forum 41: 223-30. [CrossRef]

Daly, Mary. 2015. Parenting Support as Policy Field: An Analytic Framework. Social Policy E Society 14: 597-608.

Daly, Mary, and Rachel Bray. 2015. Parenting Support in England: The Bedding Down of a New Policy. Social Policy \& Society 14: 633-44.

Demie, Feyisa, Kirstin Lewis, and Christabel MacLean. 2008. Raising the Achievement of Somali Pupils: Good Practice in London Schools. London: Lambeth Research and Statistics Unit. 
Department for Education and Employment (DfEE). 1997. Excellence in Schools. London: Her Majesty's Stationery Office.

Fisher, Jenny, Rebecca Lawthom, Zinnia Mitchell-Smith, Teresa O'Neill, and Hugh McLaughlin. 2019. ‘Neither a professional nor a friend: The liminal spaces of parents and volunteers in family support. Families, Relationships and Societies 8: 249-66. [CrossRef]

Foucault, Michel. 1991. Discipline and Punish: The Birth of the Prison. London: Penguin Books.

Foucault, Michel. 2002. Power. Essential Works of Foucault 1954-84: Volume 3. London: Penguin Books.

Foucault, Michel. 2009. Security, Territory, Population: Lectures at Collège de France 1977-78. Basingstoke: Palgrave Macmillan.

Foucault, Michel. 2012. On the Government of Living: Lectures at the Collège de France 1979-80. Basingstoke: Palgrave Macmillan.

Fretwell, Nathan, Jayne Osgood, Gill O'Toole, and Maria Tsouroufli. 2018. Governing through trust: Community-based link workers and parental engagement in education. British Educational Research Journal 44: 1047-63. [CrossRef]

Fretwell, Nathan. Forthcoming. Between Home and School: Mobilising 'hard to reach' white British parents to engage with their children's education. In Educational Research for Social Justice: Evidence and Practice from the UK. Edited by Alistair Ross. Basel: Springer Nature.

Furedi, Frank. 2008. Paranoid Parenting: Why Ignoring the Experts May Be Best for Your Child, 2nd ed. London: Bloomsbury.

Gillies, Val. 2011. From function to competence: Engaging with the new politics of the family. Sociological Research Online 16: 109-19. [CrossRef]

Gillies, Val, Rosalind Edwards, and Nicola Horsley. 2017. Challenging the Politics of Early Intervention: Who's 'Saving' Children and Why? Bristol: Policy Press.

Golder, Ben. 2007. Foucault and the Genealogy of Pastoral Power. Radical Philosophy Review 10: 157-76. [CrossRef]

Goodall, Janet. 2019. Parental engagement and deficit discourses: Absolving the system and solving parents. Educational Review, 1-13. [CrossRef]

Hartas, Dimitra. 2014. Parenting, Family Policy and Children's Well-Being in an Unequal Society: A New Culture War for Parents. Basingstoke: Palgrave Macmillan.

Hartas, Dimitra. 2015. Parenting for social mobility? Home learning, parental warmth, class and educational outcomes. Journal of Education Policy 30: 21-38. [CrossRef]

Hinds, Damian. 2018. Education Secretary Sets Vision for Boosting Social Mobility. Available online: https: //www.gov.uk/government/speeches/education-secretary-sets-vision-for-boosting-social-mobility (accessed on 15 August 2019).

Hunter, Ian. 1994. Rethinking the School: Subjectivity, Bureaucracy, Criticism. St Leonards: Allen \& Unwin.

Jensen, Tracey. 2010. Warmth and Wealth: Re-imagining social class in taxonomies of good parenting. Studies in the Maternal 2: 1-13. [CrossRef]

Jensen, Tracey. 2018. Parenting the Crisis: The Cultural Politics of Parent-Blame. Bristol: Policy Press.

Jones, Rhys, Jessica Pykett, and Mark Whitehead. 2013. Changing Behaviours: On the Rise of the Psychological State. Cheltenham: Edward Elgar.

Lee, Ellie, Jennie Bristow, Charlotte Faircloth, and Jan Macvarish. 2014. Parenting Culture Studies. Basingstoke: Palgrave Macmillan.

Martin, Graham, and Justin Waring. 2018. Realising governmentality: Pastoral power, governmental discourse and the (re) constitution of subjectivities. The Sociological Review 66: 1292-308. [CrossRef]

Martinez-Cosio, Maria, and Rosario Martinez Iannacone. 2007. The tenuous role of institutional agents: Parent liaisons as cultural brokers. Education and Urban Society 39: 107-21. [CrossRef]

Popkewitz, Thomas S. 2003. Governing the Child and Pedagogicalization of the Parent: A Historical Excursus into the Present. In Governing Children. Families and Education: Restructuring the Welfare State. Edited by Marianne N. Bloch, Kerstin Holmlund, Ingeborg Moqvist and Thomas S. Popkewitz. New York: Palgrave Macmillan. Reay, Diane. 1998. Class Work: Mothers' Involvement in their Children's Primary Schooling. London: UCL Press.

Reay, Diane. 2008. Tony Blair, the promotion of the 'active' educational citizen, and middle-class hegemony. Oxford Review of Education 34: 639-50. [CrossRef] 
Robinson, Jennifer. 2000. Power as Friendship: Spatiality, femininity and 'noisy' surveillance. In Entanglements of Power: Geographies of Domination/Resistance. Edited by Joanne P. Sharp, Paul Routledge, Chris Philo and Ronan Paddison. London: Routledge.

Rose, Nikolas. 1999a. Governing the Soul: The Shaping of the Private Self, 2nd ed. London: Free Association Books. Rose, Nikolas. 1999b. Powers of Freedom: Reframing Political Thought. Cambridge: Cambridge University Press.

Starkey, Pat. 2000. Families and Social Workers: The Work of Family Service Units 1940-85. Liverpool: Liverpool University Press.

Vincent, Carol. 2012. Parenting: Responsibilities, Risks and Respect. London: Institute of Education.

Vincent, Carol, and Claire Maxwell. 2016. Parenting Priorities and Pressures: Furthering Understanding of 'Concerted Cultivation'. Discourse: Cultural Politics in Education 37: 269-81. [CrossRef]

Wainwright, Emma, and Elodie Marandet. 2013. Family learning and the socio-spatial practice of 'supportive' power. British Journal of Sociology of Sociology of Education 34: 504-24. [CrossRef]

Wainwright, Emma, and Elodie Marandet. 2017. Education, parenting and family: The social geographies of family learning. British Educational Research Journal 43: 213-29. [CrossRef]

Waring, Justin, and Asam Latif. 2018. Of Shepherds, Sheep and Sheepdogs. Governing the Adherent Self through Complementary and Competing 'Pastorates'. Sociology 52: 1069-86. [CrossRef]

Waring, Justin, and Graham Martin. 2016. Network leadership as pastoral power: The governance of quality improvement communities in the English National Health Service. In Governmentality after Neoliberalism. Edited by Mark Bevir. London: Routledge, pp. 135-51.

Wildman, Josephine M., Suzanne Moffatt, Linda Penn, Nicola O’Brien, Mel Steer, and Colin Hill. 2019. Link workers' perspectives on factors enabling and preventing client engagement with social prescribing. Health $\mathcal{E}$ Social Care in the Community 27: 991-98.

(C) 2020 by the author. Licensee MDPI, Basel, Switzerland. This article is an open access article distributed under the terms and conditions of the Creative Commons Attribution (CC BY) license (http://creativecommons.org/licenses/by/4.0/). 